NBER WORKING PAPER SERIES

\title{
DOES DECREASED ACCESS TO EMERGENCY DEPARTMENTS AFFECT PATIENT OUTCOMES? ANALYSIS OF AMI POPULATION 1996-2005
}

\author{
Yu-Chu Shen \\ Renee Y. Hsia \\ Working Paper 16690 \\ http://www.nber.org/papers/w16690 \\ NATIONAL BUREAU OF ECONOMIC RESEARCH \\ 1050 Massachusetts Avenue \\ Cambridge, MA 02138 \\ January 2011
}

We would like to thank Jean Roth and Mohan Ramanujan at NBER for helping to extract the Medicare data, and Shouzu Lin for excellent programming assistance. We also would like to thank Laurence Baker of Stanford University for helpful comments throughout the project. This project was supported by the Robert Wood Johnson Foundation's Changes in Health Care Financing and Organization initiative (grant 63974). In addition, Hsia was supported in part by a grant under the Robert Wood Johnson Foundation's Physician Faculty Scholars Program and the National Institutes of Health/National Center for Research Resources, University of California, San Francisco Clinical and Translational Science (KL2 RR024130). The views expressed herein are those of the authors and do not necessarily reflect the views of the National Bureau of Economic Research.

NBER working papers are circulated for discussion and comment purposes. They have not been peerreviewed or been subject to the review by the NBER Board of Directors that accompanies official NBER publications.

(C) 2011 by Yu-Chu Shen and Renee Y. Hsia. All rights reserved. Short sections of text, not to exceed two paragraphs, may be quoted without explicit permission provided that full credit, including $\odot$ notice, is given to the source. 
Does Decreased Access to Emergency Departments Affect Patient Outcomes? Analysis of AMI Population 1996-2005

Yu-Chu Shen and Renee Y. Hsia

NBER Working Paper No. 16690

January 2011

JEL No. I1,I11

\begin{abstract}
We analyze whether decreased emergency department access (measured by increased driving time to the nearest ED) results in adverse patient outcomes or changes in the patient health profile for patients suffering from acute myocardial infarction. Data sources include 100\% Medicare Provider Analysis and Review, AHA hospital annual surveys, Medicare hospital cost reports, and longitude and latitude information for 1995-2005. We define four ED access change categories and estimate a zip codes fixed-effects regression models on the following AMI outcomes: time-specific mortality rates, age, and probability of PTCA on the day of admission. We find a small increase in 30-day to 1-year mortality rates among patients in communities that experience $<10$-minute increase in driving time. Among patients in communities with $>30$-minute increases in driving time, we find a substantial increase in long-term mortality rates, a shift to younger ages (suggesting that the older ones die en route) and a higher probability of immediate PTCA. Most of the adverse effects disappear after the initial three-year transition window.
\end{abstract}

Yu-Chu Shen

Graduate School of Business and Public Policy

Naval Postgraduate School

555 Dyer Road

Monterey, CA 93943

and NBER

yshen@nps.edu

Renee Y. Hsia

SFGH Medical Center

1001 Potrero Avenue

San Francisco, CA 94110

Renee.Hsia@emergency.ucsf.edu 


\section{Introduction}

According to National Center for Health Statistics, the number of EDs decreased from 4176 to 3195 between 1995 and 2005, while annual ED visits increased from 96.5 million to 115.3 million during the same period (Nawar, Niska, and Xu 2007). This trend of decreasing ED availability but increasing ED utilization continues even with the most recent data and has been noted as a major issue facing the emergency care system in the US by the Institute of Medicine (Institute of Medicine 2007; Niska, Bhuiya, and Xu 2010). There is a great deal of literature documenting decreased access to emergency departments, as summarized in the Synthesis Report by the Robert Wood Johnson Foundation and Report by the Institute of Medicine(DeLia, and Cantor 2009; Institute of Medicine 2007). While there are many anecdotal reports or singlehospital case studies suggesting the adverse effects of overcrowding and closures on patient care (Adams, and Biros 2001; Hwang et al. 2006; Pines, and Hollander 2008; Pines et al. 2007), however, there is little systematic empirical evidence to demonstrate these claims.

The principal objective of our research is to examine whether decreased ED access (measured by increased driving time to the nearest ED) results in adverse patient outcomes or changes in patient health profiles. We focus on acute myocardial infarction (AMI) patients, a group that has relatively homogenous patient characteristics and should be quite sensitive to the availability of ED care. Specifically, we address the following research questions:

1. Does increased driving time to the nearest ED result in increased mortality rates among AMI patients?

2. Does increased driving time to the nearest ED result in changes in health profile of AMI patients who arrived alive in the hospital?

3. If decreased ED access has an adverse effect on patient outcomes, is the adverse effect 
transitory or permanent?

The primary data sources for ED availability are the American Hospital Association annual surveys and Medicare Provider Analysis and Review (MedPAR) for 1995-2005. We identified the AMI population by extracting from 100\% MedPAR records. We link each patient's zip code with longitude and latitude coordinates using Mailer’s software(Mailer's Software 2006).

Finally, using the longitude and latitude coordinates of the hospital's physical address or heliport (if exist) (Horwitz, and Nichols 2009), we calculated driving time between each patient to the nearest ED.

We expand the previous literature on ED access in several ways. First, we capture permanent ED closure even in hospitals that did not close down. Second, we provide national estimates of the effect of decreased ED access on patient outcomes. Third, we examine whether there are changes in patient health profiles when distance to ED changes. Finally, we explore potential temporal effects.

\section{Background Literature}

It is well-documented that the US has experienced decreases in access to emergency departments, whether it be measured by closures of EDs or increasing hours that EDs are temporarily closed to ambulance traffic due to overcrowding or lack of available resources (California Medical Association 2001; DeLia, and Cantor 2009; Derlet 2002; Donovan 1991; General Accounting Office 2001; Hart, Pirani, and Rosenblatt 1991; Lambe et al. 2002; Lambe et al. 2003; Malone, and Dohan 2000; Melnick et al. 2004; Nawar et al. 2007; Niska et al. 2010;

Olshaker, and Rathlev 2006; Pitts et al. 2008; Schull et al. 2001; Sinay 1998; Sun et al. 2006). While there is a growing body of research suggesting adverse effects of crowding and closures 
on patient care, they are all based on data collected from single hospital settings (Bernstein et al. 2009; Fee et al. 2007; Hwang et al. 2006; Pines, and Hollander 2008; Pines et al. 2007). There is little systematic empirical evidence to demonstrate these claims.

There have been a few studies that link decreased ED access to deterioration in process measures for cardiac patients, none of which use nationally representative data. One study found that ED crowding, as measured by patients' perceived waiting time, is positively associated with increased rates of patients who are left without being seen(Vieth, and Rhodes 2006). Schull and colleagues found that simultaneous ambulance diversion at multiple EDs increased transport times and total out-of-hospital interval delays for cardiac patients (Schull et al. 2003), and that ED crowding is positively associated with increased time to thrombolytic for acute myocardial infarction (Schull et al. 2004).

Besides the limited studies that link ED access to process measures, we are not aware of any large-scale studies showing actual changes in patient outcomes due to changes in geographical access to ED. There has been only one study that links hospital closures to health outcomes, done in LA County between 1997 and 2003. This study showed that increased distance to the closest hospital, regardless of whether the hospital offers ED services, were linked to increased deaths from MI and unintentional injuries (Buchmueller, Jacobson, and Wold 2006).

\section{Conceptual Framework}

AMI is a time-sensitive illness. In our study, we focus on how changes in distance to the closest ED affect health outcomes of AMI patients while taking into account whether the nearest hospital has a cath capacity. For this paper, we obtain patient characteristics from the Medicare inpatient claims, thereby focusing on AMI patients who survived their acute onset of AMI long 
enough to generate a hospital admission record. The probability of surviving a heart attack long enough to have a hospital admission record depends on several factors: age, the initial severity of illness, and time to arrival at ED. There are several straightforward predictions when arrival is delayed:

1. When travel time increases, older patients are more likely than younger patients to have died en route, holding all other factors constant.

2. Severity of illness can increase with increased travel time, holding all other factors constant.

3. People with more severe cases of heart attack have lower probability of survival than those with milder cases of heart attack, holding all other factors constant.

When the nearest ED is closed, it effectively delays arrival time to ED for such a patient. We hypothesize that decreased ED access would affect our patient population in the following ways:

1. Patients who survived to have hospital records would be younger in areas with decreased ED access than those in areas with no decrease in ED access.

2. The observed mortality rates of all AMI patients would increase when ED access increases, but the observed mortality rates of patients who survived to have a hospital record might not.

3. Due to deterioration of condition associated with delayed TOA, patients in areas with decreased ED access would arrive at the hospital with higher probability of needing a procedure for immediate intervention.

Specifically, in our empirical model, we test these hypothesis by examining 3 types of AMI outcomes: (1) time-specific mortality rates (7-day, 30-day, 90-day, 180-day, and 1-year mortality), (2) age at the time of hospital admission, and (3) probability of receiving 
percutaneous transluminal coronary angioplasty (PTCA) on the day of admission. Finally, there is one additional factor that is likely to affect our hypotheses presented so far: the availability of catheterization lab. The use of this technology is known to improve the health outcomes of AMI patients.(Kontos et al. 2010; Stukel et al. 2007) Our empirical model will explicitly control for the availability of cath lab in the nearest facility.

\section{Study Design}

Overview. We take a difference-in-differences approach to estimate the effect of ED closure on AMI health outcomes. Consider the following hypothetical example between two groups of patients:

\begin{tabular}{|l|l|l|l|}
\hline AMI mortality rates & $\begin{array}{l}\text { Time to ED does } \\
\text { not increase } \\
\text { between } 1995 \text { and } \\
1996\end{array}$ & $\begin{array}{l}\text { Time to ED } \\
\text { increases between } \\
1995 \text { and } 1996\end{array}$ & $\begin{array}{l}\text { Difference between } \\
\text { control and treatment } \\
\text { groups }\end{array}$ \\
\hline 1995 & $14 \%$ & $16 \%$ & $2 \%$ \\
\hline 1996 & $9 \%$ & $14 \%$ & $5 \%$ \\
\hline Difference-in-differences: & & $5-2=3 \%$ \\
\hline
\end{tabular}

The 3\% increase in AMI mortality in the above example can be attributed to ED closure while accounting for secular trends (such as improvements in treatment and decreases in mortality of AMI).(Gillum 1994; McGovern et al. 1996; Rosamond et al. 1998) More specifically, we identify the effects of ED access by comparing outcomes of AMI population between the following groups: (1) people who live in zip codes with no increase in driving time to their closest ED (the control group); and (2) people who live in zip codes that experience $<10,10-30$, or $>30$ minute increases in driving time. These time thresholds were used based on knowledge of the importance of timely care for AMI patients and the empirical distribution of the driving time change. We implement zip codes fixed-effects models and include year dummies, full 
interaction of patient demographics information and several risk adjustment variables as available from claims data. We focus on the AMI population for several reasons. First, AMI usually requires immediate medical attention; therefore patient selection into hospitals based on health status or other unobservable characteristics is minimized. Second, because AMI is the leading cause of death in the elderly population, the substantial amount of claims data for this condition allows us to generate more robust findings. Third, AMI is a condition that is sensitive to the availability of ED care.

Data Sources and Patient Population. The primary data sources for ED availability are the American Hospital Association annual surveys. Because AHA data is based on self-report and may be prone to reporting errors, we modified the AHA data the following ways: (1) we use California OSHPD facility data, an administrative database, to verify ED status for California hospitals; and (2) When hospitals did not report whether they offered a service in a given year, we impute the values using information from adjacent years. Patient data, including patient's mailing zip codes, were obtained from MedPAR. We link each patient's zip code with longitude and latitude coordinates of each zip code using Mailer's software.(Mailer's Software) Finally, using the longitude and latitude coordinates of the hospital's physical address or heliport (if exist) we calculated driving time between each patient to the nearest ED.

We identified the AMI population by extracting from 100\% MedPAR records that has 410.x0 or 410.x1 as the principal diagnoses between 1995 and 2005. We apply several exclusion criteria to the patient sample. First, we follow McClellan et al's exclusion criteria to minimize selection bias (McClellan, McNeil, and Newhouse 1994). While the exclusion list is extensive, we highlight two important criteria here: we exclude transfers and patients who had a prior AMI admission within the past 12 months. We apply additional exclusion criteria pertinent to our 
study. First, we exclude 23 percent of the patient population who were not admitted through the ED, since direct admission to ED is the relevant population based on our conceptual framework that relates driving time changes to health outcome changes, and because cardiac patients directly admitted to the hospital (e.g., who present to their primary care physician's office and are admitted through their physician, bypassing the ED) are likely different in terms of severity from those admitted via the ED. Second, we exclude 11 percent of patients whose admitted hospital is more than 100 miles away from their mailing zipcodes, as those patients are likely not reside in their mailing address or were admitted to hospitals while away from home. Third, we exclude zip codes that experience multiple changes in distance to their closest ED during the study period (3 percent of the sample) as these patients do not represent patients who have experienced a single change and would not contribute to answering the original research question. Finally, we exclude zip codes that do not have patients both before and after the access change occurred (1 percent). The final sample consists of approximately 150,000 patients per year from 1996 to 2005 for a total sample size of 1.49 million patient-year observations. ${ }^{\mathrm{i}}$

\section{Methods}

Defining AMI Outcomes. We examine the following health characteristics of AMI population: mortality rates of different time horizon (7-day, 30-day, 90-day, 180-day, and 1year), age at the time of hospital admission, and whether the patient underwent PTCA on the day of admission. The three types of outcomes allow us to explicitly test the hypotheses set forth in the conceptual framework.

Defining Changes in Access to ED between 1996 and 2005. In this study, our key variable of interest is each patient's time to the nearest ED and, more importantly, whether patients reside 
in locations where driving time to ED has increased during the study period. We first calculated the distance between each zip code to the nearest ED using the population centroid location of the zip code, separately for each year.ii The distance calculation based on longitude and latitude coordinates is highly correlated with actual driving distance.(Love 1979; Phibbs, and Luft 1995) Next, we computed the change in distance between adjacent years for each zip code community. To give a better sense of the extent of change each zip code faces and to provide clarity in presenting the multivariate results, we translated changes in distance to changes in driving time using the formula by Phibbs and Luft.(Phibbs 2008; Phibbs, and Luft 1995) Finally, we classified the communities according to whether the driving time between a community and the nearest ED satisfied the following condition between 1996 and 2005: (1) did not increase (the control group); (2) increased by less than 10 minutes; or (3) increased by 10-30 minutes; and (4) increased by more than 30 minutes. We divided the treatment groups into the above three categories for easier interpretation of results and to allow for the possibility that the effect might not be linear over travel time. The fixed-effects model effectively compares the outcome differences before and after the driving time increase occurs among patients in the treatment group to the change in outcome across years among patients in the control group.

Statistical Methods. We estimate the effect of increased driving time to ED as follows:

$$
Y_{i j t}=\alpha_{t}+\beta_{1} I n c 100_{j t}+\beta_{2} I n c 10 \_30_{j t}+\beta_{3} I_{n} \lg 300_{j t}+\beta_{4} c a t h_{j t}+\beta_{5} X_{i j t}+\beta_{6} W_{i t}+Z_{j}+\varepsilon_{i j t}
$$


where

$Y_{i j t}=$ health outcome of patient $i$ residing in zip code $j$ in year $t$

$\alpha_{t}=$ year indicator

Inc $10_{j t}=1$ for zip code $j$ on and after year $t$ if time to closest ED increases

by less than 10 minutes in year $t ; 0$ otherwise.

Inc $10 \_30_{j t}=1$ for zip code $j$ on and after year $t$ if time to closest ED increases

by $10-30$ minutes in year $t ; 0$ otherwise.

Incgt $30_{j t}=1$ for zip code $j$ on and after year $t$ if time to closest ED increases

by at least 30 minutes in year $t ; 0$ otherwise.

cath $_{j t}=1$ if the closest ED in zipcode $j$ has cath lab available in year $t ; 0$ otherwise.

$\mathrm{X}_{i j t}=\mathrm{a}$ vector of demographics and comorbidity variables of patient $i$.

$W_{i t}=$ a vector of hospital characteristics of patient $i$ 's admitted hospital.

$Z_{j}=$ zip-codes fixed effects.

We estimate model (1) separately for the health outcomes described above. For the mortality and PTCA variables, we use a linear probability model with zip codes fixed effects. Even though the natural choice of estimating a dichotomous dependent variable is a probit or logit model, these models might result in inconsistent estimator, because we are including significant number of zip code fixed effects (Buchmueller et al. 2006). The linear probability models can consistently estimate the effect of changes in driving time on these mortality outcomes and require substantially less computing time (Greene 2002). For age, a continuous variable, we use least square fixed-effects models to estimate the effect of ED access on age.

In model (1), the year indicator would capture the macro trends of the AMI mortality from 1996 to 2005 . The zip codes fixed effects control for any unobserved time-invariant heterogeneity across zip codes (including any inherent differences in baseline mortality rates across communities). The variables of interest are the three access change indicators (Inc10,Inc10_30 and Incgt30) that capture the difference-in-differences estimators. Using the model with 7-day mortality rates as an example, the coefficient on Inc10 indicates that the AMI 
7-day mortality rates have changed by $\beta_{1}$ percentage point after driving time to the nearest ED in the patients whose zip codes increased by $<10$ minutes compared to the control group; likewise for $\beta_{2}$ and $\beta_{3}$. ${ }^{\text {iii }}$ The control variables, $X$ 's, include fully interacted patient demographic covariates (5-year age groups, gender, white, black or other race, counts of comorbidities, and urban or rural residence). In the model where age is the outcome of interest, we do not include age groups when constructing the fully interacted patient demographic covariates. We define zip codes as in urban area if it belongs to a Metropolitan Statistical Areas (MSA). We also include a list of disease related risk adjustment following Skinner and Staiger (2008); specifically, if patients have peripheral vascular disease, chronic pulmonary disease, dementia, chronic renal failure, diabetes, liver disease, or cancer at the time of admission. Last we include hospital organizational characteristics of the admitted hospital, including hospital ownership (for-profit, government) and size (measured by log transformed total inpatient discharges). For all models, we estimate robust standard errors that allow for intra-zipcode correlation among patients who belong to the same zip code.

When the nearest EDs were closed, patients might only experience temporary adverse effect of the closure, as communities might be able to realign their resources to compensate for the ED closure. In addition, the AHA reporting period for each hospital varies for a given annual survey - a hospital that indicate it no longer offers ED in the 2003 survey might in fact closed the service sometime in 2002. It is also possible that an ED that closed might already experience difficulties in providing care due to reasons that eventually led to its closure (e.g., lack of available resources) a few years before closure occurred. In model 2, we investigate the potential transitory effect by adding transition indicators. Specifically, for each ED access change category, we allow the effects to differ by the following transition year indicators: 2-3 
years before the access change, 1 year before to 1 year after the change, 2-3 years after the change, and 4 or more years after the change.

We estimate our models on two samples: on the whole sample and on patients whose zip codes have no more than 2 hospitals within 10-mile radius (about 30 minute drive time) in the baseline. Large increases in driving time are more likely to occur in areas with limited access to hospitals. Comparing patient outcomes in those communities directly to the general AMI population may not be fair comparison. The two sets of analysis would allow us to examine whether the results are robust to differences in baseline access to hospitals.

\section{Results}

We find that $89.2 \%$ of the study population did not experience increased driving times to their nearest ED during the study period. Figure 1 shows that shares of patients that experienced $<10,10-30$, and $>30$ minute increase in driving time were $8.9,1.7$, and $0.2 \%$, respectively. To delineate which zip codes are affected by the increased driving time, we show the ED access change categories on a US map in Figure 2. As the figure shows, large increases tend to occur in mountainous or desert regions.

Figure 3 displays the year trend in four AMI outcomes (7-day, 30-day mortality rates, average age, and share receiving PTCA on the day of admission) between 1996 and 2005. In general, AMI mortality rates have decreased over this time period, consistent with previous literature. There is an increasing trend in the average age of our study population (by about 2.5 years), as well as increased share of patients receiving PTCA on the day of admission (from 5 percent to 17 percent). 
Figures 4-5 compare the unadjusted trends by the 4 ED access change categories. Because each affected community experiences access change in a different year and we have shown in Figure 3 that trends in all outcomes do not stay flat, we normalize the trend and show the "relative" trend where the average value for each year is normalized to be zero. In other words, a hospital whose 7-day mortality rate is below national average for a given year would have a negative value. In these two graphs, the $\mathrm{X}$-axis represents the relative year to when the access change occurred (for a zipcode that experience access change in 1998, year 0 would be 1998, and year -1 would be 1997). By construction, the control group is represented by the flat line at zero across all years. As an example, for 7-day mortality rates (Figure 4, left panel), the group of patients that experience less than a 10-minute or 10-30 minute increase in driving time (red and green dashed line) have mortality rates similar or slightly below that of the control group. Among patients with $>30$ minute increase in driving time, 7-day mortality rates trend upward two years prior to the access change and then trend downward the year after the change occurred. The trend in age profile (Figure 5, left panel) also shows an interesting pattern among the communities with >30 minute increase: the baseline average age tends to be younger than that in the control group; age exhibits a decreasing trend 1 years prior to the change and bounce back to a similar age level as the baseline 2 years after change occurred. It should be noted that because the smallest sample size is in the $>30$ minute category (sample size shown at the bottom of Table 1), the trend is not as smooth as the other access change categories. The opposite pattern is observed for share of patients receiving PTCA on the day of admission: the share spikes upward for this access category two years prior to the access change and return to baseline level two years after the change. The fixed-effects models control for the baseline differences in 
outcome across the four groups of ED access change, since our identification comes from comparing within-group changes in outcome between treatment and control groups.

Table 1 presents the descriptive statistics of the independent variables by the four ED access change categories. For the control group (patients in zip codes with no increased driving time), we show the average values over all years; for the three treatment groups, we show the average values before the access change occurred. In general, patient and hospital characteristics do not appear to differ much across the access categories except for the following: As expected, patients who experience large increase in driving time are mostly in rural communities (among for those with a >30 minute increase, only 17 percent are in zipcodes that belong to a MSA). Their access to hospitals is also more limited: the average number of hospitals within 10-mile radius in the control group is 2.57 compared to 1.03 hospitals among patients who experience greater than a 30-minute increase in driving time.

Table 2 presents the fixed-effects results for model 1. The top panel shows the results of the overall Medicare AMI ED population. For moderate increases in driving time (under 30 minutes), there appear to be no differences in mortality rates (full regression results are available upon request), with one exception: for patients in communities with a $<10$-minute increase in driving time, 180 -day mortality rate rose by 0.6 of one percentage point $(\mathrm{p}<0.10)$. The last row of top panel shows that having a catheterization lab in the nearest facility appears to lower the 7day and 30-day mortality rates by 0.5 of one percentage point, but such an improvement in mortality rates disappear when looking at longer time horizon. For patients with $>30$ minutes increase in driving time, the adverse effect appears when we examine long-term mortality: overall 180-day and 1-year mortality rates increased by 5 percentage points. The bottom panel of Table 2 reports the results limiting the sample to those patients with access to 2 or fewer 
hospitals within 10-mile radius in the baseline. The adverse effects on mortality rates become magnified across all time horizons for patients facing a $<10$-minute increase in driving time. Specifically, relative to the control group, the mortality rates among this group of patients increased by 1-2 percentage points after the access change occurred. The positive and significant increase persists when we look examine at longer time horizon (up to 1 year after admission). The rest of the results on mortality rates for the other two ED access change categories are similar to the top panel.

The last two columns of Table 2 show the results on age and probability of receiving PTCA on the day of admission. The results are similar whether we look at the whole sample or the sample with limited baseline access. For the patients experience a $>30$-minute increase in driving time, the effect is consistent with the conceptual framework-the average age declined by 0.8 years but there were no observed differences in the probability of receiving PTCA. For patients that experience a less than 10 minute increase in driving time, the probability of receiving PTCA dipped by about $0.6-0.9$ of one percentage point.

Table 3 shows the estimated effects from model 2 where we add transition indicators for each access change categories. Results from this table show how the effects of the transition years can be masked when we only look at the overall effect as in Table 2. For clarity of presentation, we report only the results of the second sample where we limit patients to those with at most 2-hospital access within 10-mile radius at the baseline since this sample represents a more comparable control group (whole sample results are available upon request). Recall in Table 2 we saw increased mortality rates among patients in areas with a $<10$-minute increase in driving time after the access change took place. Table 3 suggests that most of those adverse effects are transitory: the adverse effect peaks mostly one year before the access change occurred 
(1.5-3 percentage points, depending on the time horizon), persists at a similar level up to 3 years after the change, but gradually decreases its magnitude when we look beyond the initial 3-year window. The results on age shows that the temporary increase in mortality rates is not due to changes in patient population age- there is no difference in age between control group and this group during the initial 3-year window, although the average went up slightly (by 0.4 of one year) beyond this window.

Similar to model 1 , we do not find any noticeable increase in mortality rates or transition effect on age and probability of receiving PTCA among patients experiencing 10-30 minute increase in driving time. For patients living in communities that experience a $>30$ minute increase in driving time, we observe an alarming trend in long-term mortality rates. The oneyear mortality rates is increased by 5.6 percentage points during the initial transition years, and such increase did not go away - the increase in 1-year mortality rates persists and goes up to almost 8 percentage points when we look beyond the first three years.

The last two columns of Table 3 shows that the drop in average age that we observed in Table 2 is temporary. The average age dropped by one year only during the initial transition time (from 1 year before to 1 year after the change occurred). Similarly, the share of patients receiving PTCA on the day of admission only temporarily increased by 3.9 percentage points during that window.

Sensitivity analysis. As we discussed in the conceptual framework, our sample includes only people who have an inpatient claim (this includes patients who have been admitted to the ED first and then later admitted to the hospital). Our sample does not include patients who died upon arrival or in the ED—-those people would only have outpatient record. We obtained authorization to access 3 years of outpatient records (1996, 2000, and 2005) and we explore a 
few issues related to this excluded group. First, we found that less than 7 percent of the AMI population has outpatient claims only. Second, this group tends to have much higher mortality rates than the patients that eventually were admitted to the hospital: their average in-hospital mortality rate is 22 percent in 1996 compared to 14 percent in the main sample. When we added this group to our original sample, the pattern we observe in Figures 4-5 remain similar, and our conclusions on the key ED access change variables remain the same.

Our main model only includes people who were admitted directly to the ED. In another sensitivity analysis, we include all patients, and our conclusion remains similar with one important difference: when examining the whole AMI population, we do not observe increased long-term mortality rates among patients facing >30-minute increase in driving time (perhaps not surprisingly, those who were admitted to the ED has a higher mortality rates on average than the whole sample).

\section{Discussion}

Hospital-based emergency departments are, as stated by the Institute of Medicine(Institute of Medicine 2007), at a breaking point, with increasing ED utilization and decreasing number of EDs available. In this paper, we assemble a longitudinal national dataset to address one of the key issues regarding the relationship between ED access and patient outcomes. Our empirical results provide the first national estimates of the effect of ED access on health outcomes for the AMI population and can be summarized as follows: First, ED access deterioration, as measured by increased driving time to the nearest ED, affects less than 11 percent of the population. Second, small increases in driving time (under 10 minutes) have a small adverse effect on mortality rates, and the magnitude of the effect is greater for those with 
limited access to hospitals at baseline. Third, large increases in driving time (over 30 minutes) increase the observed long-term mortality rates and also change the health profile of the admitted patients (such as younger age, and faced with higher probability of receiving PTCA on the day of admission). Last, the observed adverse effects are mostly temporary: all outcomes return to similar levels as the pre-change period beyond the initial three-year transition window, except for long-term mortality rates for those facing $>30$-minute increase—-the effect lingers and becomes stronger when looking beyond the transition window.

It is important to recognize that we focus exclusively on geographic access alone and its effect on patient outcomes. While this is an important aspect of access especially for illness where time is critical, there are other ED access issues that we cannot address in this study, such as financial or cultural barriers. ${ }^{\text {iv }}$ Persons in communities with "easy” geographic access to ED might still experience worse outcomes if other barriers worsen over time.

The study has several limitations. First, our distance variable is based on the longitude and latitude information of the ZIP code’s population center. Even though this distance measure is highly correlated with driving distance,(Phibbs, and Luft 1995) two people from the same zip code might have very different access to the same ED, especially in rural areas. A related concern is that the zip code on file is based on mailing zip code, which might not reflect the actual residence. While there is no one variable from the Medicare claims that can identify patients who were treated for AMI away from home or whose residence is different from mailing address, we took the standard approach and applied an exclusion criteria of dropping 11 percent of patients whose admitted hospital is more than 100 miles away from his zip code.

Second, we identify the nearest ED using multiple sources to minimize reporting errors and we err on the side of conservative. However, it is inevitable that some errors will remain. As 
long as the errors do not systematically differ by the access categories we examined, we do not expect to have a bias in our estimated ED access effect. Third, our patient population consists of Medicare patients who are not in managed care plans, since MedPAR is the only source of data with reliable outcome information at the national level for multiple years. Patient characteristics might have changed within this sample as more elderly are moved into managed care settings (i.e., those remained in the sample are sicker and older over time). We believe the movement to managed care would have a minimal impact on our estimated ED access effect, since there is no evidence to suggest that such movement is systematically linked to changes in area ED access.

Fourth, our data does not allow us to capture quality of pre-hospital care (i.e., care of the patient by paramedics in the ambulance en route to the hospital). If changes in the quality of EMS care varied systematically with changes in ED availability, our estimation would be biased. However, we are not aware of studies that show such a relationship and studies looking at skill levels of pre-hospital in the US generally did not find much differences in outcome for cardiac patients (Guly et al. 1995; Mitchell et al. 1997; Nguyen-Van-Tam et al. 1997; Rainer, Marshall, and Cusack 1997). The EMS community acknowledges that delays to the ED are detrimental, and we capture that dimension by using driving time as the proxy. Fifth, we were not able to differentiate between the more severe cases of AMI (ST-elevation MI, or "STEMI"), where immediate access to cath/angioplasty is critical(Boersma et al. 1996), from other AMI cases, because the diagnostic code for STEMI was officially assigned only after October 2005. It is likely that the adverse effects we observe might be of higher magnitude for STEMI.

Sixth, we are unable to ascertain whether the closed hospitals are systematically different in quality than those that remain opened. Previous literature suggests that there are a wide variety of reasons for closure,(Bromberg 1983; Chapman 1990; Kennedy, and Dumas 1983; Lillie- 
Blanton et al. 1992; Lynn, and Wertheim 1993; McNeil, and Williams 1978; Mullner, and McNeil 1986; Topping 1991; Whiteis 1992). It is very possible that ED closures were due to smaller or poorer-performing hospitals. Given this, however, our findings would be conservative since mortality would be biased downward if better hospitals preferentially survived. Similarly, while PTCA was used as a proxy for more severe illness due to delay in ED arrival, it is possible that the rates of PTCA were higher in patients who traveled further because their next available ED is a higher-volume, more tertiary center where PTCA was available and therefore utilized. However, our results show that the increase in PTCA is only temporary (also, our model controls for availability of catheterization lab), whereas we would expect the PTCA rate to persist at a higher level if the increased PTCA rate were due to better access to catheterization lab as a result of the nearby closure.

Our findings raise several important issues regarding the resource allocation of the emergency care system in general. While worse geographic access can cause a delay in care, it is not the only contributing factor. Our findings of adverse effects on mortality rates among communities experience only a small increase in driving time may indicate potential problems facing the remaining nearby hospitals when one ED closes. These affected communities are mostly in urban settings with dense population where the EDs are already experiencing overcrowding. The influx of patients the remaining hospitals have to absorb is likely to exacerbate the overcrowding conditions in their EDs (as shown in other studies, such as Sun et al 2006(Sun et al. 2006) and Dombrosk and Tracy 1978 (Dombrosk, and Tracy 1978) and can potentially cause the observed spike in mortality rates. But it appears that these communities' ED systems were able to realign their resources eventually, since the adverse effect went away after the initial three-year transition window. 
Even though only a very small segment of the population experienced a large increase in driving time to the nearest ED, the adverse effect of ED access deterioration shows up in multiple dimensions. Unlike the communities with small increase in driving time where all adverse effects disappear beyond the first three years, the increase in long-term mortality rates for this segment of the population is substantial and persistent. The drop in average age among the admitted patients is consistent with our conceptual framework that predicts that patients in these communities who survived to have hospital records are younger than those in the control group, since the older patients are more likely to die en route given the large increase in driving time. In an exploratory analysis, we also noted that number of AMI hospital admissions for this group dropped relative to the other treatment and control groups during the transition years, an observation consistent with the conceptual framework. This implies that the true effect on mortality rates is even larger, when we take into account the deaths from this segment of the patients that can potentially be prevented in the absence of the large increase in driving time. In addition, the implications for medical costs and loss of quality of life may not be trivial when we consider that those who experience large increases in driving time have a higher probability of receiving PTCA immediately compared to the control group during the transition years. The deterioration in condition might have been prevented in the absence of such change of access.

As we discussed earlier, the adverse effects we estimated should be considered the lower bound of the true effect because we only observe patients who survive to have a hospital record. Future research to confirm these findings would require capturing a more comprehensive patient population, as well as better adjustment for clinical illness (which are limited in administrative datasets). Such knowledge is critical to validate the effects of such decreased availability of services on patient outcomes. In addition, there are other conditions where time is critical and 
affects a larger segment of the population (such as severe cases of asthma, sepsis, or trauma).

Examining these conditions could reveal different issues regarding the role of ED access on patient outcomes, and provide additional insight on the best practice of resource allocation to optimize emergency care services as a whole.

Overall, there is reason to be optimistic: almost all of the adverse effects disappear after four years. ED closure, and the accompanied change in access for the affected population, is not necessarily detrimental if the closure allows patients to get to better quality hospitals that have the capacity to absorb the additional patient load. Our results suggest that policy planners can minimize the adverse effects during the transition years by facilitating the realignment of health care resources during this critical period. Potential solutions might involve providing assistance to ensure adequate capacity of remaining operating EDs in the area before the closure even took place, and improved coordination among the various EMS players.

\section{Endnotes}

i 1995 was not used in the analysis because it was used to exclude patients from 1996 who had prior AMI admissions.

${ }^{\text {ii }}$ We used the population centroid of 2000 for the calculation.

iii Because the AHA reporting period for each hospital varies for a given annual survey, we turn the access change indicator to one the year before the hospital said it closes the ED (i.e., a hospital that indicate it no longer offers ED in the 2003 survey might in fact close the service sometime in 2002).

${ }^{\text {iv }}$ Waiting time, while an important issue for patients with non-urgent conditions, is unlikely a cause of delay for AMI patient. Chest pain patients presenting to the ED are prioritized in triage and in almost all hospitals receive an electrocardiogram while in triage. 


\section{Reference}

Adams, J. G. and M. H. Biros. 2001. "The endangered safety net: establishing a measure of control.” Acad Emerg Med 8(11): 1013-5.

Bernstein, S. L., D. Aronsky, R. Duseja, S. Epstein, D. Handel, U. Hwang, M. McCarthy, K. John McConnell, J. M. Pines, N. Rathlev, R. Schafermeyer, F. Zwemer, M. Schull, and B. R. Asplin. 2009. "The effect of emergency department crowding on clinically oriented outcomes." Acad Emerg Med 16(1): 1-10.

Boersma, E., A. C. Maas, J. W. Deckers, and M. L. Simoons. 1996. "Early thrombolytic treatment in acute myocardial infarction: reappraisal of the golden hour." Lancet 348(9030): 771-5.

Bromberg, M. D. 1983. “Hospital closures.” Health Serv Res 18(4): 579-81.

Buchmueller, T., M. Jacobson, and C. Wold. 2006. "How far to the hospital?The effect of hospital closures on access to care.” Journal of Health Economics 25(4): 740-61.

California Medical Association. 2001. "California's emergency services: a system in crisis.” 44. Chapman, T. W. 1990. "Hospital viability and closures." J Health Care Poor Underserved 1(1): 96-102; discussion 03-6.

DeLia, D. and J. Cantor. 2009. “Emergency department utilization and capacity.” Research Syntehsis Report. Princeton, NJ: The Robert Wood Johnson Foundation.

Derlet, R. W. 2002. "Overcrowding in emergency departments: increased demand and decreased capacity.” Ann Emerg Med 39(4): 430-2.

Dombrosk, S. and R. M. Tracy. 1978. "Impact of hospital closures on nearby hospitals studied.” Hospitals 52(23): 82-5, 129.

Donovan, M. R. 1991. “An endangered resource. Hospital emergency departments are threatened by closures and a reduction in services.” Health Prog 72(4): 50-4.

Fee, C., E. J. Weber, C. A. Maak, and P. Bacchetti. 2007. "Effect of emergency department crowding on time to antibiotics in patients admitted with community-acquired pneumonia." Ann Emerg Med 50(5): 501-9, 09.e1.

General Accounting Office. 2001. "EMTALA Implementation and Enforcement Issues.” Washington, DC: US General Accounting Office.

Gillum, R. F. 1994. "Trends in acute myocardial infarction and coronary heart disease death in the United States.” J Am Coll Cardiol 23(6): 1273-7.

Greene, W. H. 2002. Econometric analysis. Upper Saddle River, NJ: Prentice Hall.

Guly, U. M., R. G. Mitchell, R. Cook, D. J. Steedman, and C. E. Robertson. 1995. "Paramedics and technicians are equally successful at managing cardiac arrest outside hospital.” BMJ 310(6987): 1091-4.

Hart, L. G., M. J. Pirani, and R. A. Rosenblatt. 1991. "Causes and consequences of rural small hospital closures from the perspectives of mayors.” J Rural Health 7(3): 222-45.

Horwitz, J. R. and A. Nichols. 2009. "Hospital ownership and medical services: market mix, spillover effects, and nonprofit objectives.” J Health Econ 28(5): 924-37.

Hwang, U., L. D. Richardson, T. O. Sonuyi, and R. S. Morrison. 2006. "The effect of emergency department crowding on the management of pain in older adults with hip fracture.” $J$ Am Geriatr Soc 54(2): 270-5.

Institute of Medicine. 2007. “Hospital-Based Emergency Care: At the Breaking Point.”. Washington, DC: Institute of Medicine. 
Kennedy, L. and M. B. Dumas. 1983. "Hospital closures and survivals: an analysis of operating characteristics and regulatory mechanisms in three states." Health Serv Res 18(4): 489-512. Kontos, M. C., M. C. Kurz, C. S. Roberts, S. E. Joyner, L. Kreisa, J. P. Ornato, and G. W. Vetrovec. 2010. "Emergency physician-initiated cath lab activation reduces door to balloon times in ST-segment elevation myocardial infarction patients.” Am J Emerg Med.

Lambe, S., D. L. Washington, A. Fink, K. Herbst, H. Liu, J. S. Fosse, and S. M. Asch. 2002. "Trends in the use and capacity of California's emergency departments, 1990-1999." Ann Emerg Med 39(4): 389-96.

Lambe, S., D. L. Washington, A. Fink, M. Laouri, H. Liu, J. Scura Fosse, R. H. Brook, and S. M. Asch. 2003. "Waiting times in California's emergency departments.” Ann Emerg Med 41(1): 3544.

Lillie-Blanton, M., S. Felt, P. Redmon, S. Renn, S. Machlin, and E. Wennar. 1992. "Rural and urban hospital closures, 1985-1988: operating and environmental characteristics that affect risk." Inquiry 29(3): 332-44.

Love, R. F., Morris, J.G. 1979. "Mathematical models of road travel distances.” Management Science 252: 130-39.

Lynn, M. L. and P. Wertheim. 1993. "Key financial ratios can foretell hospital closures.” Healthc Financ Manage 47(11): 66-70.

Mailer's Software. [accessed on May 22. Available at:

http://www.MelissaData.com/software.htm.

Mailer's Software. 2006. “ZIP*Data.” San Clemente, CA: Melissa Data.

Malone, R. E. and D. Dohan. 2000. “Emergency department closures: policy issues.” J Emerg Nurs 26(4): 380-3.

McClellan, M., B. J. McNeil, and J. P. Newhouse. 1994. "Does more intensive treatment of acute myocardial infarction in the elderly reduce mortality? Analysis using instrumental variables.”

Jama 272(11): 859-66.

McGovern, P. G., J. S. Pankow, E. Shahar, K. M. Doliszny, A. R. Folsom, H. Blackburn, and R. V. Luepker. 1996. "Recent trends in acute coronary heart disease--mortality, morbidity, medical care, and risk factors. The Minnesota Heart Survey Investigators.” N Engl J Med 334(14): 88490.

McNeil, D. and R. Williams. 1978. "Wide range of causes found for hospital closures.” Hospitals 52(23): 76-81.

Melnick, G. A., A. C. Nawathe, A. Bamezai, and L. Green. 2004. "Emergency department capacity and access in California, 1990-2001: an economic analysis.” Health Aff (Millwood) Suppl Web Exclusives: W4-136-42.

Mitchell, R. G., U. M. Guly, T. H. Rainer, and C. E. Robertson. 1997. "Can the full range of paramedic skills improve survival from out of hospital cardiac arrests?” J Accid Emerg Med 14(5): 274-7.

Mullner, R. M. and D. McNeil. 1986. "Rural and urban hospital closures: a comparison.” Health Aff (Millwood) 5(3): 131-41.

Nawar, E. W., R. W. Niska, and J. Xu. 2007. "National Hospital Ambulatory Medical Care Survey: 2005 emergency department summary.” Adv Data(386): 1-32.

Nguyen-Van-Tam, J. S., A. F. Dove, M. P. Bradley, J. C. Pearson, P. Durston, and R. J. Madeley. 1997. "Effectiveness of ambulance paramedics versus ambulance technicians in managing out of hospital cardiac arrest.” J Accid Emerg Med 14(3): 142-8. 
Niska, R., F. Bhuiya, and J. Xu. 2010. "National Hospital Ambulatory Medical Care Survey: 2007 emergency department summary.” Natl Health Stat Report(26): 1-31.

Olshaker, J. S. and N. K. Rathlev. 2006. "Emergency Department overcrowding and ambulance diversion: the impact and potential solutions of extended boarding of admitted patients in the Emergency Department.” J Emerg Med 30(3): 351-6.

Phibbs, C. 2008. "Patient Incurred Cost - How do I estimate travel costs?" [accessed on June 11, 2008]. Available at: http://www.herc.research.va.gov/resources/faq_h02.asp.

Phibbs, C. and H. Luft. 1995. "Correlation of travel time on roads versus straight line distance." Med Care Res Rev 52(4): 532-42.

Pines, J. M. and J. E. Hollander. 2008. "Emergency department crowding is associated with poor care for patients with severe pain.” Ann Emerg Med 51(1): 1-5.

Pines, J. M., A. R. Localio, J. E. Hollander, W. G. Baxt, H. Lee, C. Phillips, and J. P. Metlay. 2007. "The impact of emergency department crowding measures on time to antibiotics for patients with community-acquired pneumonia.” Ann Emerg Med 50(5): 510-6.

Pitts, S., R. Niska, J. Xu, and C. Burt. 2008. "National Hospital Ambulatory Medical Care

Survey: 2006 emergency department summary.” Natl Health Stat Report(7): 1-38.

Rainer, T. H., R. Marshall, and S. Cusack. 1997. "Paramedics, technicians, and survival from out of hospital cardiac arrest.” J Accid Emerg Med 14(5): 278-82.

Rosamond, W. D., L. E. Chambless, A. R. Folsom, L. S. Cooper, D. E. Conwill, L. Clegg, C. H. Wang, and G. Heiss. 1998. "Trends in the incidence of myocardial infarction and in mortality due to coronary heart disease, 1987 to 1994.” N Engl J Med 339(13): 861-7.

Schull, M. J., L. J. Morrison, M. Vermeulen, and D. A. Redelmeier. 2003. "Emergency department gridlock and out-of-hospital delays for cardiac patients.” Acad Emerg Med 10(7): 709-16.

Schull, M. J., J. P. Szalai, B. Schwartz, and D. A. Redelmeier. 2001. “Emergency department overcrowding following systematic hospital restructuring: trends at twenty hospitals over ten years.” Acad Emerg Med 8(11): 1037-43.

Schull, M. J., M. Vermeulen, G. Slaughter, L. Morrison, and P. Daly. 2004. “Emergency department crowding and thrombolysis delays in acute myocardial infarction." Ann Emerg Med 44(6): 577-85.

Sinay, U. T. 1998. "Hospital mergers and closures: survival of rural hospitals.” J Rural Health 14(4): 357-65.

Stukel, T. A., E. S. Fisher, D. E. Wennberg, D. A. Alter, D. J. Gottlieb, and M. J. Vermeulen. 2007. "Analysis of observational studies in the presence of treatment selection bias: effects of invasive cardiac management on AMI survival using propensity score and instrumental variable methods.” JAMA 297(3): 278-85.

Sun, B. C., S. A. Mohanty, R. Weiss, R. Tadeo, M. Hasbrouck, W. Koenig, C. Meyer, and S. Asch. 2006. "Effects of hospital closures and hospital characteristics on emergency department ambulance diversion, Los Angeles County, 1998 to 2004.” Ann Emerg Med 47(4): 309-16. Topping, S. 1991. "Hospital closures: what is the story?" Health Serv Manage Res 4(2): 148-58. Vieth, T. and K. Rhodes. 2006. "The effect of crowding on access and quality in an academic ED.” Am J Emerg Med 24(7): 787-94.

Whiteis, D. G. 1992. "Hospital and community characteristics in closures of urban hospitals, 1980-87.” Public Health Rep 107(4): 409-16. 


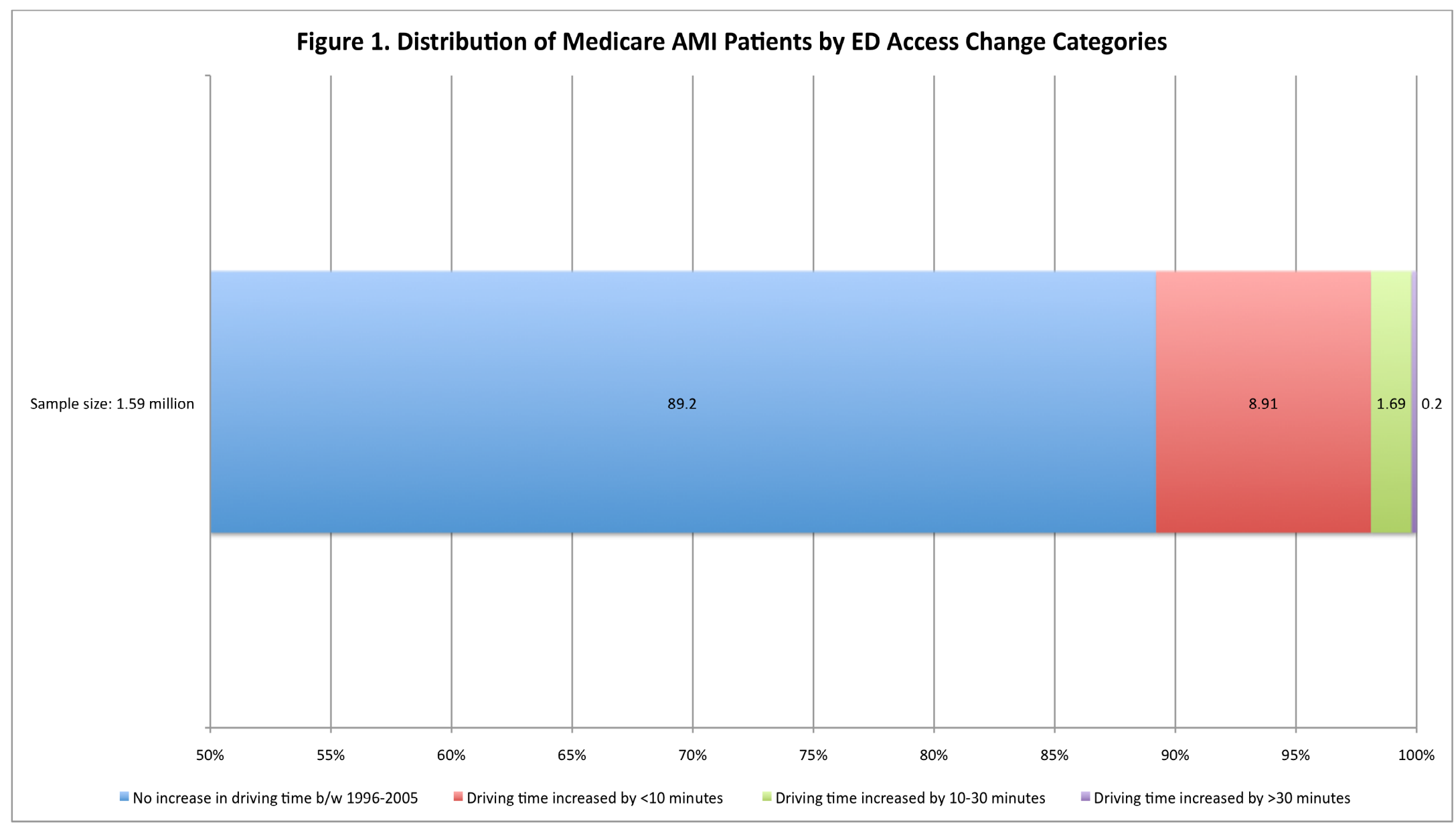


Figure 2. Geographical Distribution of ED Access Change Between 1996 and 2005

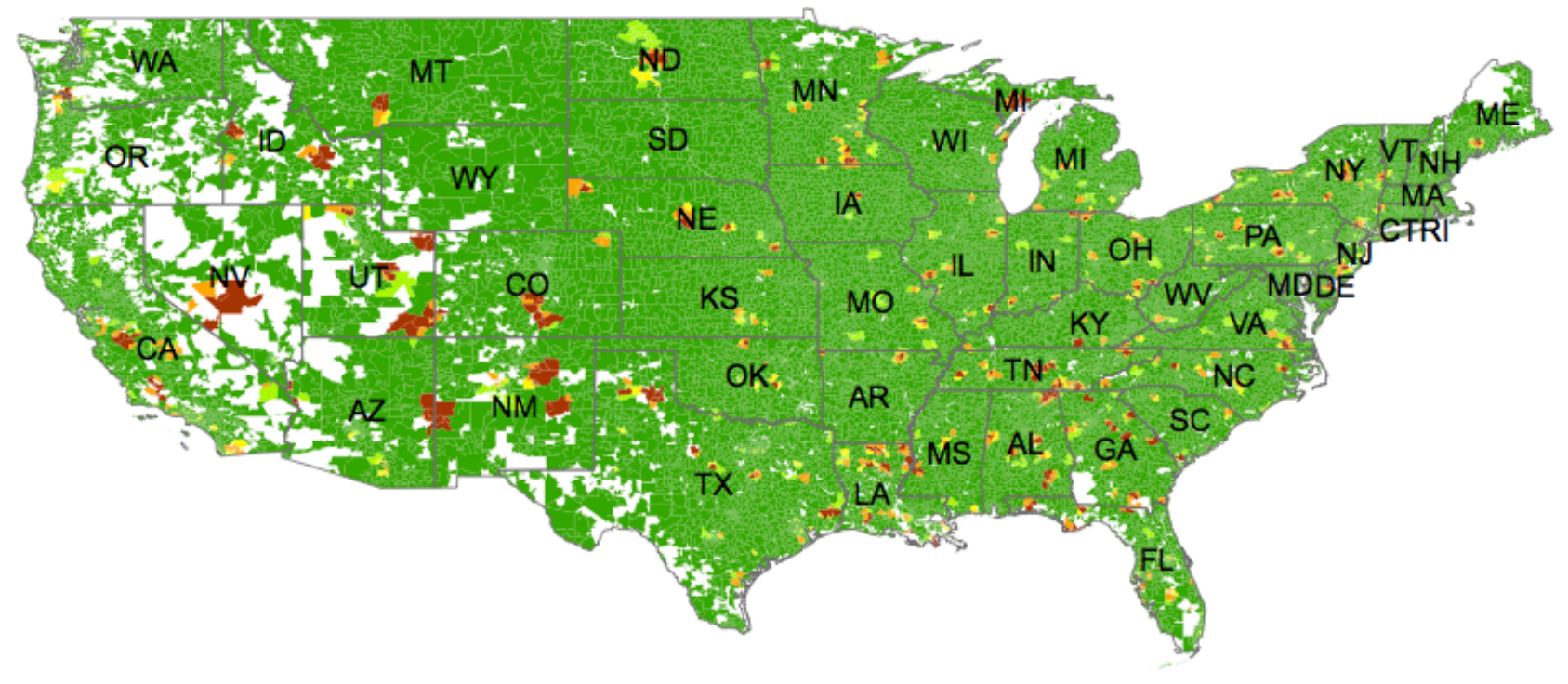

Change in driving time to ED, 1996-2005

$\square$ no data

no increase

$>0$ to 5 min increase

$>5$ to $10 \mathrm{~min}$ increase

$>10$ to $30 \mathrm{~min}$ increase

$>30$ min increase 
Figure 3: Overall Trend in AMI Health Outcomes 1996-2005
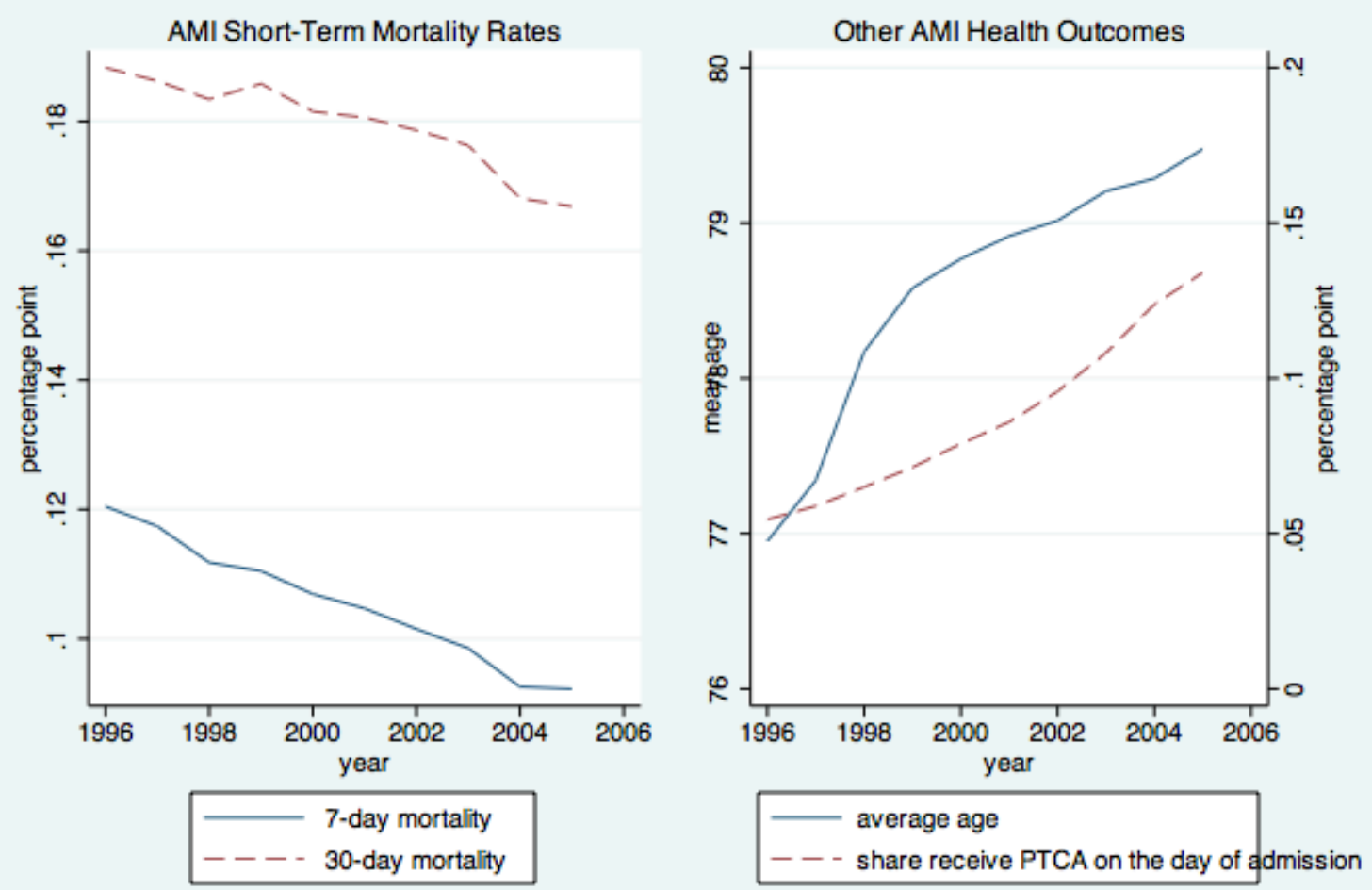
Figure 4: Relative Year Trend in Short-term AMI Mortality Rates by ED Access Change Categories
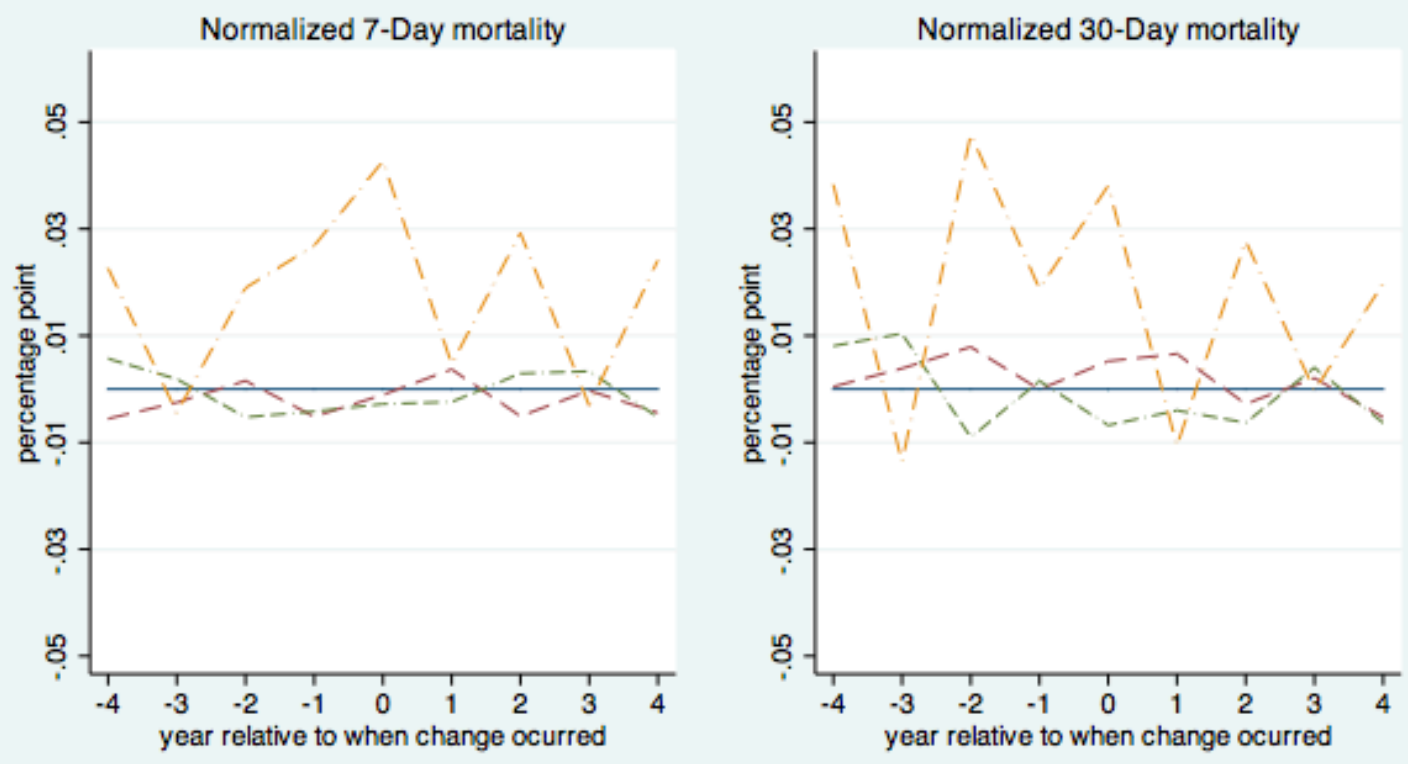

\section{No increase in ED time \\ ----- ED time increase $<10 \mathrm{~min}$ \\ ED time increase $10-30 \mathrm{~min}$ ED time increase $>30 \mathrm{~min}$}

Figure 5: Relative Year Trend in Normalized Age and PTCA Procedure by ED Access Change Categories
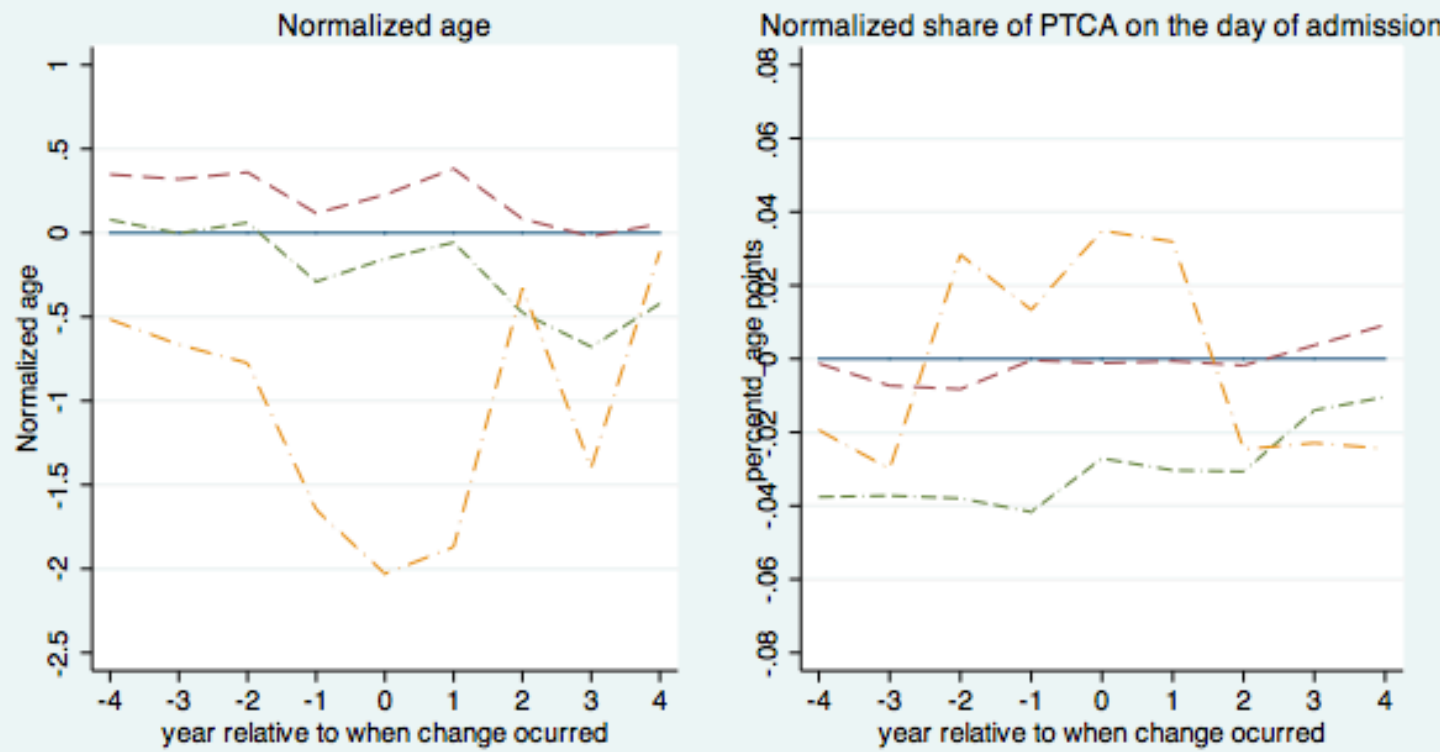

$$
\begin{aligned}
& \text { No increase in ED time } \\
& \text { ED time increase } 10-30 \mathrm{~min}
\end{aligned}
$$


Table 1. Descriptive Statistics of Patient Population By ED Access Change Categories Control Group (All Treatment Groups (Average before change year average)

\begin{tabular}{|c|c|c|c|c|}
\hline Mean (standard deviations) & $\begin{array}{c}\text { No increase driving } \\
\text { time to ED }\end{array}$ & $\begin{array}{c}\text { increase time } \\
<10 \mathrm{~min}\end{array}$ & $\begin{array}{c}\text { increase time } \\
10-30 \mathrm{~min} \\
\end{array}$ & $\begin{array}{c}\text { increase time } \\
>30 \mathrm{~min}\end{array}$ \\
\hline \multicolumn{5}{|l|}{ Patient characteristics } \\
\hline Female & $\begin{array}{c}0.51 \\
(0.50)\end{array}$ & $\begin{array}{c}0.52 \\
(0.50)\end{array}$ & $\begin{array}{c}0.50 \\
(0.50)\end{array}$ & $\begin{array}{c}0.50 \\
(0.50)\end{array}$ \\
\hline African-American & $\begin{array}{l}0.07 \\
(0.25)\end{array}$ & $\begin{array}{c}0.10 \\
(0.30)\end{array}$ & $\begin{array}{l}0.07 \\
(0.25)\end{array}$ & $\begin{array}{c}0.09 \\
(0.29)\end{array}$ \\
\hline Other non-white race & $\begin{array}{c}0.04 \\
(0.19)\end{array}$ & $\begin{array}{c}0.04 \\
(0.20)\end{array}$ & $\begin{array}{c}0.02 \\
(0.14)\end{array}$ & $\begin{array}{c}0.03 \\
(0.16)\end{array}$ \\
\hline Age & $\begin{array}{l}78.56 \\
(7.87)\end{array}$ & $\begin{array}{l}78.43 \\
(7.85)\end{array}$ & $\begin{array}{l}78.33 \\
(7.80)\end{array}$ & $\begin{array}{l}77.53 \\
(7.66)\end{array}$ \\
\hline Urban location & $\begin{array}{l}0.75 \\
(0.43)\end{array}$ & $\begin{array}{l}0.93 \\
(0.25)\end{array}$ & $\begin{array}{c}0.71 \\
(0.45)\end{array}$ & $\begin{array}{c}0.17 \\
(0.38)\end{array}$ \\
\hline Peripheral vascular disease & $\begin{array}{l}0.08 \\
(0.27)\end{array}$ & $\begin{array}{l}0.07 \\
(0.26)\end{array}$ & $\begin{array}{l}0.08 \\
(0.27)\end{array}$ & $\begin{array}{c}0.07 \\
(0.25)\end{array}$ \\
\hline Chronic pulmonary disease & $\begin{array}{l}0.22 \\
(0.42)\end{array}$ & $\begin{array}{c}0.20 \\
(0.40)\end{array}$ & $\begin{array}{l}0.23 \\
(0.42)\end{array}$ & $\begin{array}{c}0.21 \\
(0.41)\end{array}$ \\
\hline Dementia & $\begin{array}{l}0.04 \\
(0.19)\end{array}$ & $\begin{array}{c}0.04 \\
(0.19)\end{array}$ & $\begin{array}{c}0.04 \\
(0.20)\end{array}$ & $\begin{array}{l}0.03 \\
(0.18)\end{array}$ \\
\hline Chronic renal failure & $\begin{array}{c}0.02 \\
(0.14)\end{array}$ & $\begin{array}{c}0.02 \\
(0.14)\end{array}$ & $\begin{array}{c}0.02 \\
(0.15)\end{array}$ & $\begin{array}{c}0.02 \\
(0.15)\end{array}$ \\
\hline Diabetes & $\begin{array}{l}0.27 \\
(0.44)\end{array}$ & $\begin{array}{l}0.28 \\
(0.45)\end{array}$ & $\begin{array}{l}0.28 \\
(0.45)\end{array}$ & $\begin{array}{c}0.28 \\
(0.45)\end{array}$ \\
\hline Liver diseases & $\begin{array}{l}0.00 \\
(0.06)\end{array}$ & $\begin{array}{l}0.00 \\
(0.06)\end{array}$ & $\begin{array}{l}0.00 \\
(0.05)\end{array}$ & $\begin{array}{l}0.00 \\
(0.04)\end{array}$ \\
\hline Cancer & $\begin{array}{l}0.05 \\
(0.22)\end{array}$ & $\begin{array}{l}0.05 \\
(0.22)\end{array}$ & $\begin{array}{l}0.05 \\
(0.22)\end{array}$ & $\begin{array}{c}0.04 \\
(0.21)\end{array}$ \\
\hline \multicolumn{5}{|l|}{ Admitted Hospital Characteristics } \\
\hline For-profit hospitals & $\begin{array}{c}0.12 \\
(0.32)\end{array}$ & $\begin{array}{c}0.16 \\
(0.36)\end{array}$ & $\begin{array}{c}0.18 \\
(0.39)\end{array}$ & $\begin{array}{c}0.23 \\
(0.42)\end{array}$ \\
\hline Government hospitals & $\begin{array}{c}0.11 \\
(0.32)\end{array}$ & $\begin{array}{c}0.06 \\
(0.23)\end{array}$ & $\begin{array}{c}0.13 \\
(0.33)\end{array}$ & $\begin{array}{c}0.14 \\
(0.35)\end{array}$ \\
\hline Total discharges & $\begin{array}{l}11375 \\
(42526)\end{array}$ & $\begin{array}{c}8487 \\
(6735)\end{array}$ & $\begin{array}{c}5814 \\
(5068)\end{array}$ & $\begin{array}{l}1363 \\
(1004)\end{array}$ \\
\hline Number of hospitals within $10-\mathrm{m}$ & $\begin{array}{c}2.57 \\
(1.96)\end{array}$ & $\begin{array}{c}4.22 \\
(2.02)\end{array}$ & $\begin{array}{c}1.95 \\
(1.72)\end{array}$ & $\begin{array}{c}1.03 \\
(0.39)\end{array}$ \\
\hline Observations & $1,418,613$ & 65,291 & 16,366 & 1,806 \\
\hline
\end{tabular}


Table 2. Effects of Driving Time on AMI Health Outcomes

\begin{tabular}{|c|c|c|c|c|c|c|c|}
\hline & \multicolumn{5}{|c|}{ AMI Mortality Rates } & \multicolumn{2}{|c|}{ Other Outcomes } \\
\hline & 7-day & 30-day & 90-day & 180-day & 1-year & Age & $\begin{array}{l}\text { PTCA on the } \\
\text { admission day }\end{array}$ \\
\hline \multicolumn{8}{|l|}{ Whole Sample } \\
\hline all yrs after driving time inc by $<10$ min & $\begin{array}{l}-0.0002 \\
(0.0023)\end{array}$ & $\begin{array}{l}0.0029 \\
(0.0032)\end{array}$ & $\begin{array}{l}0.0046 \\
(0.0035)\end{array}$ & $\begin{array}{l}0.0061+ \\
(0.0036)\end{array}$ & $\begin{array}{l}0.0037 \\
(0.0037)\end{array}$ & $\begin{array}{l}0.0716 \\
(0.0636)\end{array}$ & $\begin{array}{l}-0.0064 * * \\
(0.0023)\end{array}$ \\
\hline all yrs after driving time inc $10-30 \mathrm{~min}$ & $\begin{array}{l}-0.0063 \\
(0.0049)\end{array}$ & $\begin{array}{l}-0.0098 \\
(0.0067)\end{array}$ & $\begin{array}{l}-0.0061 \\
(0.0074)\end{array}$ & $\begin{array}{l}-0.0026 \\
(0.0075)\end{array}$ & $\begin{array}{l}-0.0072 \\
(0.0075)\end{array}$ & $\begin{array}{l}-0.0295 \\
(0.1441)\end{array}$ & $\begin{array}{l}-0.0099 * \\
(0.0045)\end{array}$ \\
\hline all yrs after driving time inc by $>=30 \mathrm{mir}$ & $\begin{array}{l}0.0172 \\
(0.0162)\end{array}$ & $\begin{array}{l}0.0123 \\
(0.0223)\end{array}$ & $\begin{array}{l}0.0258 \\
(0.0254)\end{array}$ & $\begin{array}{l}0.0449+ \\
(0.0255)\end{array}$ & $\begin{array}{l}0.0565^{*} \\
(0.0254)\end{array}$ & $\begin{array}{l}-0.8168+ \\
(0.4303)\end{array}$ & $\begin{array}{l}0.0194 \\
(0.0154)\end{array}$ \\
\hline closest hospital has cath lab & $\begin{array}{l}-0.0046 * \\
(0.0018)\end{array}$ & $\begin{array}{l}-0.0047 * \\
(0.0022)\end{array}$ & $\begin{array}{l}-0.0034 \\
(0.0025) \\
\end{array}$ & $\begin{array}{l}-0.0026 \\
(0.0026) \\
\end{array}$ & $\begin{array}{l}-0.0036 \\
(0.0027) \\
\end{array}$ & $\begin{array}{l}-0.0887+ \\
(0.0476) \\
\end{array}$ & $\begin{array}{l}0.0017 \\
(0.0020)\end{array}$ \\
\hline Sample size & & & & & & & $1,485,44$ \\
\hline \multicolumn{8}{|c|}{ Comparable Sample ( 2 or fewer hospital access in the baseline) } \\
\hline all yrs after driving time inc by $<10 \mathrm{~min}$ & $\begin{array}{l}0.0095^{*} \\
(0.0048)\end{array}$ & $\begin{array}{l}0.0168^{*} \\
(0.0067)\end{array}$ & $\begin{array}{l}0.0203 * * \\
(0.0074)\end{array}$ & $\begin{array}{l}0.0197 * * \\
(0.0075)\end{array}$ & $\begin{array}{l}0.0165^{*} \\
(0.0074)\end{array}$ & $\begin{array}{l}0.1500 \\
(0.1275)\end{array}$ & $\begin{array}{l}-0.0091 * \\
(0.0043)\end{array}$ \\
\hline all yrs after driving time inc $10-30 \mathrm{~min}$ & $\begin{array}{l}-0.0045 \\
(0.0052)\end{array}$ & $\begin{array}{l}-0.0056 \\
(0.0074)\end{array}$ & $\begin{array}{l}-0.0045 \\
(0.0083)\end{array}$ & $\begin{array}{l}-0.0010 \\
(0.0082)\end{array}$ & $\begin{array}{l}-0.0053 \\
(0.0084)\end{array}$ & $\begin{array}{l}0.0570 \\
(0.1719)\end{array}$ & $\begin{array}{l}-0.0041 \\
(0.0050)\end{array}$ \\
\hline all yrs after driving time inc by $>=30 \mathrm{mir}$ & $\begin{array}{l}0.0178 \\
(0.0164)\end{array}$ & $\begin{array}{l}0.0126 \\
(0.0225)\end{array}$ & $\begin{array}{l}0.0269 \\
(0.0257)\end{array}$ & $\begin{array}{l}0.0466+ \\
(0.0258)\end{array}$ & $\begin{array}{l}0.0574 * \\
(0.0257)\end{array}$ & $\begin{array}{l}-0.7848+ \\
(0.4376)\end{array}$ & $\begin{array}{l}0.0212 \\
(0.0155)\end{array}$ \\
\hline closest hospital has cath lab & $\begin{array}{l}-0.0072 * * \\
(0.0025)\end{array}$ & $\begin{array}{l}-0.0060+ \\
(0.0032)\end{array}$ & $\begin{array}{l}-0.0054 \\
(0.0034)\end{array}$ & $\begin{array}{l}-0.0036 \\
(0.0035) \\
\end{array}$ & $\begin{array}{l}-0.0056 \\
(0.0036)\end{array}$ & $\begin{array}{l}-0.0533 \\
(0.0696) \\
\end{array}$ & $\begin{array}{l}-0.0018 \\
(0.0031)\end{array}$ \\
\hline Sample size & & & & & & & 789, \\
\hline
\end{tabular}

Significant at $+p<0.10 * p<0.05 * * p<0.01$ 
Table 3. Effects of Timing of Change on AMI Health Outcomes

\begin{tabular}{|c|c|c|c|c|c|c|c|}
\hline & \multicolumn{5}{|c|}{ AMI Mortality Rates } & \multicolumn{2}{|c|}{ Other Outcomes } \\
\hline & 7-day & 30-day & 90-day & 180-day & 1-year & Age & $\begin{array}{c}\text { PTCA on the } \\
\text { admission } \\
\text { day }\end{array}$ \\
\hline \multicolumn{8}{|c|}{ Comparable Sample ( 2 or fewer hospital access in the baseline) } \\
\hline \multicolumn{8}{|l|}{ Driving time inc by $<10 \mathrm{~min}$} \\
\hline $2-3$ years before access change & $\begin{array}{l}0.0055 \\
(0.0066)\end{array}$ & $\begin{array}{l}0.0209 * \\
(0.0085)\end{array}$ & $\begin{array}{l}0.0140 \\
(0.0099)\end{array}$ & $\begin{array}{l}0.0128 \\
(0.0099)\end{array}$ & $\begin{array}{l}0.0105 \\
(0.0102)\end{array}$ & $\begin{array}{l}0.0619 \\
(0.1722)\end{array}$ & $\begin{array}{l}-0.0066 \\
(0.0053)\end{array}$ \\
\hline 1 year before to 1 year after & $\begin{array}{l}0.0151 * * \\
(0.0057)\end{array}$ & $\begin{array}{l}0.0309 * * \\
(0.0072)\end{array}$ & $\begin{array}{l}0.0302 * * \\
(0.0088)\end{array}$ & $\begin{array}{l}0.0284 * * \\
(0.0087)\end{array}$ & $\begin{array}{l}0.0236 * * \\
(0.0088)\end{array}$ & $\begin{array}{l}0.0962 \\
(0.1557)\end{array}$ & $\begin{array}{l}-0.0101+ \\
(0.0057)\end{array}$ \\
\hline $2-3$ years after access change & $\begin{array}{l}0.0117 \\
(0.0075)\end{array}$ & $\begin{array}{l}0.0251 * \\
(0.0100)\end{array}$ & $\begin{array}{l}0.0257 * \\
(0.0107)\end{array}$ & $\begin{array}{l}0.0228+ \\
(0.0117)\end{array}$ & $\begin{array}{l}0.0207+ \\
(0.0108)\end{array}$ & $\begin{array}{l}0.3349+ \\
(0.1916)\end{array}$ & $\begin{array}{c}-0.0187 * \\
(0.0079)\end{array}$ \\
\hline $4+$ years after access change & $\begin{array}{l}0.0013 \\
(0.0073)\end{array}$ & $\begin{array}{l}0.0169+ \\
(0.0097)\end{array}$ & $\begin{array}{l}0.0189+ \\
(0.0111)\end{array}$ & $\begin{array}{l}0.0234^{*} \\
(0.0118)\end{array}$ & $\begin{array}{l}0.0154 \\
(0.0112)\end{array}$ & $\begin{array}{l}0.4413 * \\
(0.2128)\end{array}$ & $\begin{array}{l}-0.0153+ \\
(0.0089)\end{array}$ \\
\hline \multicolumn{8}{|l|}{ Driving time inc by $10-30 \mathrm{~min}$} \\
\hline 2-3 years before access change & $\begin{array}{l}-0.0107+ \\
(0.0059)\end{array}$ & $\begin{array}{l}-0.0138+ \\
(0.0075)\end{array}$ & $\begin{array}{l}-0.0123 \\
(0.0090)\end{array}$ & $\begin{array}{l}-0.0161+ \\
(0.0089)\end{array}$ & $\begin{array}{l}-0.0207 * \\
(0.0098)\end{array}$ & $\begin{array}{l}0.3329 * \\
(0.1639)\end{array}$ & $\begin{array}{l}-0.0068 \\
(0.0042)\end{array}$ \\
\hline 1 year before to 1 year after & $\begin{array}{l}-0.0118+ \\
(0.0062)\end{array}$ & $\begin{array}{l}-0.0110 \\
(0.0086)\end{array}$ & $\begin{array}{l}-0.0093 \\
(0.0091)\end{array}$ & $\begin{array}{l}-0.0066 \\
(0.0087)\end{array}$ & $\begin{array}{l}-0.0124 \\
(0.0091)\end{array}$ & $\begin{array}{l}0.1943 \\
(0.2099)\end{array}$ & $\begin{array}{l}-0.0100+ \\
(0.0057)\end{array}$ \\
\hline $2-3$ years after access change & $\begin{array}{l}0.0023 \\
(0.0085)\end{array}$ & $\begin{array}{l}-0.0094 \\
(0.0115)\end{array}$ & $\begin{array}{l}-0.0062 \\
(0.0131)\end{array}$ & $\begin{array}{l}-0.0094 \\
(0.0136)\end{array}$ & $\begin{array}{l}-0.0174 \\
(0.0137)\end{array}$ & $\begin{array}{l}0.2104 \\
(0.2745)\end{array}$ & $\begin{array}{l}0.0029 \\
(0.0081)\end{array}$ \\
\hline $4+$ years after access change & $\begin{array}{l}-0.0048 \\
(0.0100)\end{array}$ & $\begin{array}{l}-0.0265+ \\
(0.0136)\end{array}$ & $\begin{array}{l}-0.0264+ \\
(0.0149)\end{array}$ & $\begin{array}{l}-0.0175 \\
(0.0149)\end{array}$ & $\begin{array}{l}-0.0280+ \\
(0.0159)\end{array}$ & $\begin{array}{l}0.3879 \\
(0.3117)\end{array}$ & $\begin{array}{l}0.0066 \\
(0.0128)\end{array}$ \\
\hline \multicolumn{8}{|l|}{ Driving time inc by $>30 \mathrm{~min}$} \\
\hline $2-3$ years before access change & $\begin{array}{l}-0.0034 \\
(0.0142)\end{array}$ & $\begin{array}{l}-0.0053 \\
(0.0196)\end{array}$ & $\begin{array}{l}-0.0220 \\
(0.0212)\end{array}$ & $\begin{array}{l}0.0027 \\
(0.0258)\end{array}$ & $\begin{array}{l}0.0062 \\
(0.0257)\end{array}$ & $\begin{array}{l}0.0949 \\
(0.4330)\end{array}$ & $\begin{array}{l}0.0174 \\
(0.0185)\end{array}$ \\
\hline 1 year before to 1 year after & $\begin{array}{l}0.0172 \\
(0.0197)\end{array}$ & $\begin{array}{l}0.0061 \\
(0.0257)\end{array}$ & $\begin{array}{l}0.0097 \\
(0.0280)\end{array}$ & $\begin{array}{l}0.0390 \\
(0.0271)\end{array}$ & $\begin{array}{l}0.0565^{*} \\
(0.0287)\end{array}$ & $\begin{array}{c}-1.0677^{*} \\
(0.5030)\end{array}$ & $\begin{array}{l}0.0390 * \\
(0.0161)\end{array}$ \\
\hline $2-3$ years after access change & $\begin{array}{l}0.0120 \\
(0.0252)\end{array}$ & $\begin{array}{l}0.0217 \\
(0.0262)\end{array}$ & $\begin{array}{l}0.0236 \\
(0.0301)\end{array}$ & $\begin{array}{l}0.0637+ \\
(0.0332)\end{array}$ & $\begin{array}{l}0.0659 * \\
(0.0327)\end{array}$ & $\begin{array}{l}0.1653 \\
(0.6539)\end{array}$ & $\begin{array}{l}-0.0036 \\
(0.0247)\end{array}$ \\
\hline $4+$ years after access change & $\begin{array}{l}0.0135 \\
(0.0231)\end{array}$ & $\begin{array}{l}0.0080 \\
(0.0309)\end{array}$ & $\begin{array}{l}0.0535 \\
(0.0357)\end{array}$ & $\begin{array}{l}0.0884^{*} \\
(0.0393)\end{array}$ & $\begin{array}{l}0.0760 * \\
(0.0374)\end{array}$ & $\begin{array}{l}0.3865 \\
(0.7005)\end{array}$ & $\begin{array}{l}0.0224 \\
(0.0344)\end{array}$ \\
\hline Sample size & & & & & & & 789,735 \\
\hline
\end{tabular}

Significant at $+p<0.10 * p<0.05 * * p<0.01$ 